\title{
A IMPORTÂNCIA ESTRATÉGICA DO TERCEIRO SETOR NO BRASIL COMO MEIO DE DESENVOLVIMENTO SOCIAL: UMA ARGUMENTAÇÃO TEÓRICA A PARTIR DO PRISMA DA ECONOMIA SOCIAL DE GIDE
}

Maurin Almeida Falcão*

Rayanne Saturnino de Araujo**

SUMÁRIO: Introdução. 2. As justificativas teóricas para o Terceiro Setor: uma variação em torno do tema da Economia Política, da Economia Social e da democracia participativa. 2.1. A Economia Social em Gide e a modelagem teórica da ação coletiva. 2.2. O vazio social e a emergência do Terceiro Setor. 2.3. A noção de sociedade civil, a democracia participativa e a coesão social. 3. O papel estratégico do Terceiro Setor no Brasil. 3.1. A atuação do Terceiro Setor na prestação de serviços públicos. 3.2. Perspectivas e desafios para o Terceiro Setor no Brasil: a necessidade de um quadro jurídico consolidado. 4. Conclusão. Referências.

RESUMO: O presente artigo tem o escopo de apresentar e discutir um modelo teórico que possa sustentar o debate em torno da importância estratégica do Terceiro Setor no Brasil. Com base no método hipotético-dedutivo, a partir do qual se conduz uma argumentação com supedâneo na lição de Charles Gide e nos conceitos de Economia Política, o trabalho estabelece uma conexão estreita entre os fundamentos da Economia Social e do Terceiro Setor uma vez que este tema ainda permanece desconhecido por boa parte dos segmentos sociais. As falhas do mercado e do Estado levaram a um vazio social e a emergência do Terceiro Setor foi então uma resposta da sociedade civil organizada com vistas ao estabelecimento dos novos paradigmas do processo social. A redução das desigualdades sociais, da pobreza e a maior participação do cidadão no processo social deixaram de ser um problema apenas do Estado. O Terceiro Setor se constitui em ação estratégica não apenas por despertar todos para a importância do voluntariado mas também por se constituir em um promissor mercado de trabalho no Brasil. Além disso, se revela um meio importante de redução do custo das políticas públicas tendo em vista a proximidade da sua atuação junto à sociedade civil, o que permite uma maior eficiência alocativa dos escassos recursos públicos. Todo esse processo viria acompanhado, sem dúvida, de um esforço de harmonização do aparato legislativo que rege a matéria.

PALAVRAS-CHAVE: Democracia participativa; Economia Social; Sociedade civil; Terceiro Setor.

Pós-doutor pela Universidade de Paris I-Panthéon-Sorbonne. Professor do Programa de Mestrado em Direito, do curso de Direito e de Relações Internacionais da Universidade Católica de Brasília, Brasil.

E-mail:mfalcao@pos.ucb.br

** Mestranda no Programa de Pós-Graduação em Ciência Política na Universidade Federal de Goiás (UFG), Brasil. 


\title{
THE STRATEGIC IMPORTANCE OF THE BRAZILIAN THIRD SECTOR AS A MEANS FOR SOCIAL DEVELOPMENT: A THEORETICAL ARGUMENTATION FROM GIDE'S SOCIAL ECONOMIC POINT OF VIEW
}

\begin{abstract}
A theoretical model that would foreground a debate on the strategic importance of the Third Sector in Brazil is provided and discussed. Foregrounded on the hypothesis-deduction method with argumentation based on Charles Gide's doctrine and on the concepts of Political Economy, current essay establishes a connection between the bases of Social Economy and the Third Sector. In fact, the theme is largely unknown among social segments. Since market and State faults brought social emptiness, the emergence of the Third Sector was a response to organized civil society to establish new paradigms for the social process. Decrease in social inequalities, poverty and a greater participation of citizens in the social process are no longer merely problems of the State. The Third Sector is a strategic activity not merely to reveal the importance of voluntary activities but also a promising labor market in Brazil. Further, it is a means for cost reduction in public policies due to their closeness to civil society which allows a greater allocation of scanty public resources. The process would doubtlessly be followed by a harmonic effort of the legislation on the matter.
\end{abstract}

KEY WORDS: Participatory democracy; Social economy; Civil society; Third sector.

\section{LA IMPORTANCIA ESTRATÉGICA DEL TERCER SECTOR EN BRASIL COMO MEDIO DE DESARROLLO SOCIAL: UNA ARGUMENTACIÓN TEÓRICA A PARTIR DEL PRISMA DE LA ECONOMÍA SOCIAL DE GIDE}

RESUMEN: El presente artículo tiene el objetivo de presentar y discutir un modelo teórico que pueda sustentar el debate sobre la importancia estratégica del Tercer Sector en Brasil. Con base en el método hipotético-deductivo, a partir del cual se conduce una argumentación con supedáneo en la lección de Charles Gide y en los conceptos de Economía Política, el estudio establece una conexión estrecha entre los fundamentos de la Economía Social y del Tercer Sector una vez que este tema aún sigue desconocido por gran parte de los segmentos sociales. Las fallas del mercado y del Estado llevaron a un vacío social y la emergencia del Tercer Sector fue entonces una respuesta de la sociedad civil organizada con vistas al establecimiento de los nuevos paradigmas del proceso social. La reducción de las desigualdades sociales, de la pobreza y la mayor participación del ciudadano en el proceso social dejaron de 
ser un problema sólo del Estado. El Tercer Sector se constituye en acción estratégica no sólo por despertar todos para la importancia del voluntariado, pero también por constituirse en un promisor mercado de trabajo en Brasil. Además de eso, se revela un medio importante de reducción del costo de las políticas públicas teniendo en vista el acercamiento de su actuación junto a la sociedad civil, lo que permite más eficiencia al designar los escasos recursos públicos. Todo ese proceso vendría acompañado, sin duda, de un esfuerzo de armonización del aparato legislativo que rige la materia.

PALABRAS-CLAVE: Democracia participativa; Economía Social; Sociedad civil; Tercer Sector.

\section{INTRODUÇÃO}

Embora tenha surgido no seio da sociedade civil, o Terceiro Setor ainda permanece desconhecido de boa parte dos segmentos sociais que o compõem. A sua dimensão e os seus contornos teóricos se constituem em uma zona cinzenta até mesmo nos meios acadêmicos. Contudo, por detrás desta iniciativa existe toda uma concertação destinada a preencher o vazio social deixado pelo Estado e pelo mercado. Se ambos falharam no sentido de permitir uma melhor redistribuição da riqueza social e perderam a confiança dos indivíduos, os fins propostos pelo Terceiro Setor tiveram, pelos menos, a intenção de remediar determinados males sociais a partir do associativismo, dentre outras modalidades de ação com vistas a atenuar as desigualdades sociais.

É importante observar que essa constatação foi responsável pelo surgimento de um número significativo de teorias destinadas a definir e a justificar o meio no qual se inseriria a atuação do Terceiro Setor. Para isso, utilizou-se o stock das ideias concebidas ainda no Século XIX, acerca da construção dos Estados sociais, conforme ressaltado por Aron mais adiante. Com efeito, a mudança social ocorrida na sociedade pós-Revolução Industrial abalizaria todo e qualquer debate em torno da solidariedade, da redistribuição da riqueza social e do intervencionismo estatal. A busca pela compreensão dos fenômenos sociais deu início à sociologia. Das lições dos percussores desse campo de conhecimento buscou-se entender a nova paisagem social contemporânea, marcada por mudanças significativas no que se refere ao papel do Estado e de suas instituições com vistas à coesão social. 
É nesse novo mosaico social que se insere o Terceiro Setor. Qual é a sua exata dimensão teórica e estratégica? Qual é o seu impacto junto à sociedade civil, de onde emergiu? São questões que o presente trabalho se propõe a desenvolver. Em um primeiro momento, a análise volta-se para a formulação teórica do Terceiro Setor a partir da noção de Economia Social exposta por Gide. Ainda nessa primeira abordagem, o trabalho expõe os conceitos importantes para a compreensão do tema como as questões pertinentes à coesão social, à sociedade civil e à democracia participativa.

Em um segundo momento, o trabalho se debruçará sobre o papel estratégico do Terceiro Setor no Brasil, suas perspectivas e desafios no campo da justiça social. Não obstante os esforços desprendidos por parcelas importantes da sociedade civil, inclusive pelo próprio alcance do segmento, o Terceiro Setor tem sido objeto de certa indiferença ou desinteresse por partes importantes do corpo social, até mesmo no meio acadêmico. Assim sendo, o presente trabalho se propõe a contribuir com o debate, inserindo uma vertente teórica que, se não esgota o tema, pelo menos lança uma luz sobre a importância da atuação do Terceiro Setor.

\section{AS JUSTIFICATIVAS TEÓRICAS PARA O TERCEIRO SETOR: UMA VARIAÇÃO EM TORNO DO TEMA DA ECONOMIA POLÍTICA, DA ECONOMIA SOCIAL E DA DEMOCRACIA PARTICIPATIVA}

As falhas do mercado no Século XIX, no alvorecer da sociedade industrial, levaram ao advento do Estado intervencionista, o único então capaz de prover as necessidades dos indivíduos no contexto do desequilíbrio entre o capital e o trabalho. Posteriormente, após mais de um século de primazia no cenário sociopolítico, em meados dos anos setenta do Século XX, o Estado providência começaria a demonstrar sinais de esgotamento. Fustigado por mais de três décadas pelos adeptos do Mont-Pélérin, o intervencionismo estatal conheceria um ocaso após a consagração do autor do "Caminho da servidão". Hayek seria laureado pelo Prêmio Nobel de Economia em 1974, ano no qual, por coincidência, se constituiria no marco inicial da crise do Estado e de suas instituições o fim dos Trinta Gloriosos e o início da crise econômica internacional.

Portanto, as falhas do mercado e do Estado levaram à reorganização da sociedade civil, antes anestesiada pelos excessos intervencionistas. Orestabelecimento 
dos laços que sempre uniram a grande sociedade solidária relançou o ideal proposto por Durkheim, por ocasião da mudança social ocorrida na sociedade pós-Revolução Industrial. Por isso, a expressão"Terceiro Setor" tem merecido uma atenção especial da Sociologia por ter despertado no consciente coletivo a retomada da ação solidária diante do vazio social ocasionado pelas falhas do mercado liberal e da relativa inércia do Estado. A partir daí, com o agravamento da crise do setor público nas décadas seguintes, a convergência de vontades com vistas à manutenção da coesão social, desencadeou o processo de parcerias entre a sociedade civil e o Estado. Deve ser notado que esse processo ocorreu de forma natural como consequência da degradação social que grassava o cenário sociopolítico. Tal movimento atingiria não apenas as economias periféricas mas também países de envergadura econômica, como é o caso notável dos Estados Unidos. Com efeito, o "Third Sector" conheceria uma expansão importante mesmo diante da pregação neoliberal que marcaria os anos Reagan no início dos anos oitenta do Século XX.

A sinergia estabelecida entre o Estado, o mercado, como provedores dos recursos necessários, e a sociedade civil, com o trabalho voluntário e as estruturas não governamentais, concorreram para o êxito do Terceiro Setor. Hoje, esse segmento se constitui em uma variável importante da vida em sociedade e a sua atuação ocorre nos mais diversos extratos sociais tendo inclusive incorporado, em tempos recentes, as questões relacionadas à proteção ambiental.

Nesses novos tempos, não obstante a pregação com vistas ao fim das ideologias, não se pode desprezar o forte conteúdo socioliberal que impregna o Terceiro Setor. De fato, seria possível colocá-lo em uma visão pragmática, como algo pertencente à pós-modernidade e até à nova estética do capital, supostamente mais humana. Contudo, seriam os fundamentos da solidariedade durkheiniana que levaria à configuração do Terceiro Setor de hoje. Sem dúvida, o sociólogo e a sociologia daquele tempo voltaram-se para o novo papel do Estado e das instituições próprias do progresso social, fato marcante no período pós-Revolução Industrial. Dessa forma, não há como desvincular a atuação do Terceiro Setor nos dias atuais, do embasamento teórico que marcou o advento da grande sociedade solidária. A riqueza do pensamento social, proveniente de diferentes escolas, tornou-se uma referência teórica conforme Aron, em suas antológicas lições sobre a sociedade industrial, notou que "vivemos com o stock das ideias desenvolvidas pelos pensadores daquela época e nada é mais útil, para fixar a originalidade da nossa 
situação atual, do nos referirmos à situação do século passado"03. A pluralidade das ideias ali forjadas resultaria no binômio formado pela democracia e pela questão social, o que conduziria as sociedades no rumo dos novos horizontes de liberdade. Como assinalou Donzelot, "O social aparece como uma invenção necessária para tornar governável uma sociedade que optou pela democracia" ${ }^{04}$.

A sociedade democrática definiu os contornos do Estado social e participava da construção da grande sociedade solidária ao financiar a ação social do Estado por meio do tributo. Nesse aspecto, aliás, vê-se sem dificuldades que o Estado brasileiro, por exemplo, manteve essa lógica por meio do regime tributário destinado ao Terceiro Setor, previsto na Constituição Federal. A imunidade constitucional reforçou a ideia de que todos concorrem para o bem-estar social. Talvez, este seja o elo mais forte entre o Estado e a sociedade civil.

Remontando, portanto, às origens do solidarismo é que se poderá compreender melhor o debate em torno do papel do Terceiro Setor como corre em nossos dias.

\subsection{A ECONOMIA SOCIAL EM GIDE E A MODELAGEM TEÓRICA DA AÇÃO COLETIVA}

O tema da economia política leva inexoravelmente à argumentação desenvolvida em torno dos conceitos de Economia Política, de Economia Política aplicada e de Economia Social. A partir da compreensão desses domínios é possível obter uma melhor compreensão de parte dos fundamentos sociológicos que justificariam o surgimento do Terceiro Setor. Por vezes, é possível se deparar com equívocos no manuseio de um conceito ou de outro, sendo que não é incomum a colocação em campos distintos, da Economia Social e da Economia Política. Contudo, o fim aqui proposto é o de situar no plano científico a ação do Terceiro Setor e o seu correto enquadramento e área de atuação. Todavia, não se pretende esmiuçar as atividades próprias desse segmento importante para a coesão social. Tendo em vista que a sua atuação perpassa os diversos segmentos da vida em sociedade, o Estado, o mercado e a sociedade civil, o esforço para se definir os contornos sociopolíticos do Terceiro Setor se constitui em tarefa difícil. Não obstantes essas dificuldades conceituais, verifica-se que o mesmo faz parte de uma

\footnotetext{
$\overline{03}$ ARON, Raymond. Dix-huit leçons sur la société industrielle. Paris: Galimard, 1962, p. 33.

${ }^{04}$ DONZELOT, Jacques. L'invention du social. Paris: Éditions du Seuil, 1994, p. 127.
} 
longa maturação do pensamento social e do esforço científico desprendido a partir da eclosão da sociedade industrial. Se por um lado a Revolução Industrial contribuiu para o incremento do processo de urbanização e a criação de novos modos de produção, pelo outro foi responsável pelo surgimento de mazelas sociais na esteira do desequilíbrio entre o capital e o trabalho. Assim, a partir do socialismo utópico de Saint-Simon, da sociedade solidária de Durkheim, da igualdade de condições de Tocqueville e da luta de classes de Marx, a sociedade foi capaz de moldar a questão social dentro de princípios humanísticos, oferecendo um contraponto à lógica que impulsiona o mercado.

Deve ser observado que a Economia Política no seu sentido amplo abarcou também a questão social por atrair para a sua órbita não apenas as questões ligadas à produção da riqueza como também a satisfação e a felicidade das pessoas. Entretanto, para isso, foi preciso disponibilizar os meios materiais necessários para tanto. Posteriormente, ao final do Século XX, o tema evoluiu para uma Economia Política do contrato social, expressão cunhada por Fitoussi e Rosanvallon, onde foi exposto que os sistemas de proteção estariam voltados para as demandas com vistas à seguridade social, à solidariedade e à estabilização ${ }^{05}$. Percebe-se, sem dificuldades, que se trata de demandas que na sua essência estão relacionadas à intervenção do Estado e às falhas do mercado. Contudo, indo mais além, tem-se que a crise do Estado, verificada após os anos setenta do Século XX, não permitiu o prosseguimento dessas ações com a mesma efetividade daquelas despendidas a partir do modelo concebido após a Segunda Guerra Mundial. Deve ser observado que esta seria uma das razões para o movimento de reorganização da sociedade civil. Essa perspectiva leva à releitura das teses da Economia Social, um termo que não é novo e que faz parte do universo da Economia Política. Gide argumentou no sentido de estabelecer uma relação estreita entre os dois campos de investigação. Entretanto, o amálgama de tal associação foi identificado por Weber que, em largo exercício sobre economia e sociedade, discorreu sobre o Sozialökonomik e a evolução para um oïkos das relações da comunidade doméstica com a economia ${ }^{06}$.

Gide definiu os objetivos da economia política a partir das relações decorrentes da vida dos homens em sociedade, os quais procuram satisfazer as suas

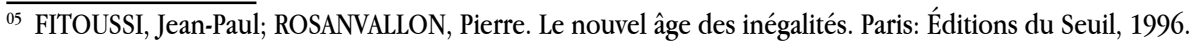

${ }^{06}$ WEBER, Max. Economie et société - l'organisation et les puissances de la société dans leurs rapports avec l'économie. Tradução de Julien Freund et alii. Paris: Plon, 1971.
} 
necessidades materiais e, dessa forma, obtêm o seu bem-estar ${ }^{07}$. Por isso, contestou os argumentos utilizados por Smith, Ricardo e Say que, em princípio, estabeleceriam a economia política como sendo a ciência da riqueza. Entretanto, Gide refutou esta definição por entender que a mesma desviaria o real objetivo da ciência econômica "[...] que seria o homem e as suas necessidades, concentrando sobre os objetos exteriores ao homem que são apenas meios para satisfazer as suas necessidades" ${ }^{\prime 0}$.

Este seria o seu argumento principal para descrever o campo de atuação da Economia Política que seria, posteriormente, dividido em duas ordens de estudo. A primeira estaria relacionada diretamente à noção de Economia Política aplicada. Nesse caso, voltado à identificação dos meios para se incrementar a riqueza de um país. É nessa similitude conceitual que Gide vai ao encontro de Smith, Ricardo e Say e até mesmo dos fisiocratas. É importante observar que este domínio concentra as grandes questões da Economia Política aplicada, voltada para a produção, redistribuição, circulação e o consumo de riquezas. Embora não faça parte da presente análise, cabe lembrar que o consumo seria considerado como uma forma de destruição da riqueza, como observado pelas doutrinas econômicas.

A segunda ordem de estudo, contida no espectro geral da Economia Política, seria a Economia Social, a qual se debruçaria sobre os meios para tornar os homens mais felizes e nessa medida, se volta, segundo Gide "[...] para as relações voluntárias que estes criam entre si sob a forma de associações, leis escritas ou instituições, com vistas à melhoria de suas condições e como a melhor forma de atingir este fim e tornam os homens mais felizes" 09 .

De forma inconteste, os valores perseguidos pela Economia Social estariam vinculados estreitamente àqueles do tempo da construção do socialismo utópico. Não apenas Saint-Simon, por meio de suas obras que retratavam as questões morais e filosóficas do industrialismo mas também Robert Owen que, preocupado com a introdução de reformas sociais, empreendeu na Inglaterra, durante a Revolução Industrial, iniciativas pioneiras no que se referem aos objetivos da Economia Social, no contexto do socialismo utópico. Em realidade, as difíceis condições do proletariado no período que se seguiu à Revolução Industrial despertaram todos para uma "démarche" social com vistas a propiciar o suporte científico para o progresso em curso. O florescimento de ciências voltadas para a análise do comportamento do

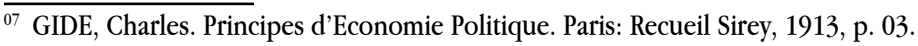

${ }^{08}$ Ibid.

${ }^{09}$ Ibid, p. 04.
} 
corpo social, do mercado e do Estado, se constituiu em um importante supedâneo para o avanço da Sociologia e da Economia Política, no seu sentido lato. Os novos modos de produção trazidos pela Revolução Industrial viriam a confirmar as previsões dos teóricos da Economia Política aplicada e tudo formava um circuito ótimo, desde a produção, distribuição, circulação até o consumo de riquezas. Se, de um lado, o mercado já havia definido a sua estratégia de atuação, restava ainda pendente a questão social, daí porque um debate de envergadura ganhou a primazia de notáveis pensadores ao longo de mais de dois séculos.

Com a mudança social do Século XIX, o termo estaria relacionado para sempre à busca dos remédios práticos para os problemas sociais e que estes seriam decorrentes da aplicação das leis da economia política clássica ${ }^{10}$. O aparecimento de um Direito Social resgatou os valores do naturalismo, criando uma espécie de norma social onde a socialização do risco se constituiu em seu princípio basilar. A grande sociedade solidária se ocuparia dessa tarefa. A participação de todos era algo coercitivo e apesar dos protestos das minorias organizadas, foi este o modelo concebido e que perdura até os dias atuais, não obstante o incessante combate para colocar por terra as virtudes ainda que discutíveis da ação social do Estado. A relação vertical instaurada no seio da sociedade pós-Revolução Industrial permitiria o início de um significativo processo de redistribuição de riquezas. O tributo se constituiria na pedra angular desse processo daí porque a contestação do modelo colocado em prática durante a mudança social do século das luzes, uma vez que o sacrifício fiscal atingiria a todos. Como se verá mais adiante e trazendo a questão para a atualidade, com referência ao tema contemplado nesse trabalho, é possível constatar que o êxito da atuação do Terceiro Setor no Brasil se deve também à importante participação do Estado que, por intermédio do sistema constitucional tributário, concedeu privilégios justificados a esse segmento importante da vida em sociedade. Visando aplacar os efeitos do vazio social, o Estado brasileiro se mostrou receptivo às propostas do Terceiro Setor, disponibilizando o quadro legal necessário para uma maior participação da sociedade civil.

Retomando a discussão acerca do dilema entre Economia Política aplicada e Economia Social, cabe ressaltar que Gide aplainou as críticas daqueles que as colocavam em campos opostos. Em realidade, conforme observado por Weber, haveria sempre uma ordem econômica, social e jurídica, podendo ser constatado

\footnotetext{
${ }^{10}$ DONZELOT, Jacques, op. cit., p. 125.
} 
dessa assertiva que todo processo resulta da convergência dos valores de um ou de outro campo de estudo. Esses campos de investigação forneceram as bases científicas para uma Economia Política no sentido lato. Dessa forma, se hoje nos deparamos com uma sociedade organizada é porque ainda vivemos com o stock de ideias observado por Aron.

\subsection{O VAZIO SOCIAL E A EMERGÊNCIA DO TERCEIRO SETOR}

Apesar da separação ocorrida entre os dois campos de estudo, conforme estabelecido por Gide, é possível assim mesmo apontar uma convergência dos valores intrínsecos a cada um deles. Se a Economia Política Aplicada voltou-se para a riqueza e a Economia Social para a busca dos meios de se tornar os homens mais felizes, ambas expõem, contudo, a disputa pela riqueza social, colocada de forma escassa à disposição de todos. Walras definiu a riqueza social como sendo "l'ensemble des choses matérielles ou immatérielles qui sont rares, c'est-à-dire, d'une part, nous sont utiles, et qui, d'autres part, n'existent à notre disposition qu'n quantité limitée"11. A organização do processo redistribuidor da riqueza social se constituiria, portanto, em discórdia uma vez que o acesso a ela se daria de forma conflituosa. O mercado já havia sinalizado a lógica na qual seria pautado o acesso à riqueza social ao se constituir em um trunfo para o bomus economicus. A divisão social do trabalho se encarregaria de organizar essas forças no sentido de contemplar aqueles com maiores habilidades. Desse pressuposto, pode-se apontar então uma das razões da falha do mercado em contribuir para o incremento do bem-estar dos indivíduos. Por sua vez, o Estado, chamado para resolver a pendência do vazio social deixado pelo mercado, passou a intervir nas relações entre o capital e o trabalho, dando início assim a um polêmico período. Esta intervenção levou o Estado a acumular parte da riqueza social, tendo isto concorrido para a cobiça dos grupos sociais de diferentes matizes. Como resultado da mudança social na fase pós-Revolução Industrial, não apenas a minoria organizada como também os trabalhadores organizados em fábricas passaram a reivindicar uma maior participação no processo de redistribuição da riqueza social.

Contudo, o transcorrer do século abalaria as bases do Estado intervencionista, o qual foi submetido a um fogo cerrado após a sua desmesurada expansão, ao final do

${ }^{11}$ WALRAS, Léon. Éléments d'économie politique. Paris: Librairie Général de Droit et de Jurisprudence, 1952, p. 21. 
segundo conflito mundial. Sem dúvida, a ampliação das áreas de atuação do Estado e de suas novas organizações foi objeto de contestação das correntes liberais que, finalmente, triunfaram ao final dos Trinta Gloriosos. A retomada dos valores liberais e a crise do Estado impuseram uma nova lógica na redistribuição da riqueza social. Com isso, um grave desequilíbrio social viria a gerar desigualdades persistentes, mesmo diante das tentativas registradas em tempos recentes, de se recuperar, ao menos, parte do que foi perdido. Iniciativas como o imposto negativo, adotado em diversas economias como forma de oferecer um paliativo às desigualdades sociais.

Mesmo diante desse quadro, não é difícil concluir que o Estado falhou em decorrência da crise internacional dos anos setenta do Século XX, dando início à "uma nova questão social traduzida pela inadaptação dos antigos métodos de gestão do social", como ressaltou Rosanvallon ${ }^{12}$. O vazio social deixado pela crise do Estado e pelas falhas do mercado levou a sociedade civil a se organizar com o intuito de encontrar novas soluções para os velhos problemas aos quais o Estado intervencionista tinha trazido certo paliativo. Assim, foi inaugurado um novo tempo para a Economia Social tal como conhecemos em nosso tempo, tendo sido designada por Piriou como cooperativas mutualistas e certas modalidades associativas e que "S'est historiquement constituée pour répondre à des besoins peu ou mal pris en compte par le marché ou par l'État"13, tudo se inserindo nos contornos definidos por Gide para uma Economia Social. Sem dúvida, a Economia Social se estruturou em tornos de temas constantes da agenda das sociedades industriais e passou a definir, segundo Batifoulier, "un intervale fermé entre l'État et le marché"14. Tendo incorporado as questões sociais latentes como a luta contra a pobreza, a redução das desigualdades e da solidariedade entre gerações, a Economia Social se consolidou por meio desses fundamentos os quais lhe garantiram o estofo científico necessário à sua inserção no cenário sociopolítico.

Por isso, a reorganização da sociedade civil ocorreu talvez nos mesmos moldes e amplitudes da mudança social da sociedade pós-Revolução Industrial. Assim, iniciou-se uma etapa importante nas relações sociais em face da atuação pungente do que passou a ser denominado de Terceiro Setor. A degradação social registrada após a crise do Estado, notadamente nos países periféricos, onde um significativo processo de urbanização agravaria as condições mínimas do bem-estar,

\footnotetext{
${ }_{12}$ ROSANVALLON, Pierre. La nouvelle question sociale. Paris: Éditions du Seuil, 1995, p. 07.

13 PIRIOU, Jean-Paul. Lexique de sciences économiques et sociales. $4^{\mathrm{a}}$ ed. Paris: La Découverte, 2001, p. 42.

${ }^{14}$ BATIFOULIER, Philippe. L'économie sociale. Paris: Presses Universitaires de France, 1995, p. 05.
} 
atuou como um motor importante para esta reorganização. Aliada a esta variável, temse ainda a crise da democracia em diversos países da América Latina, por exemplo, o que veiria a agravar ainda mais a questão social. A regulação das economias pelos organismos internacionais seria outro fato importante para o agravamento desse quadro. Inúmeras economias foram submetidas aos ditames de regras oriundas, em sua maioria, das novas escolas do pensamento econômico, responsáveis pela formulação das diretrizes emanadas por estes organismos. Portanto, com a crise do Estado e da democracia, foram reunidos os ingredientes necessários que levariam os indicadores sociais para patamares críticos. À nova questão social se juntavam também a questão relativa ao trabalho e à redução da renda dos trabalhadores, além do desemprego. Era inauguradao, portanto, o período de recrudescimento das desigualdades sociais.

Em face, talvez, de uma nova mudança social, o bomo socioligucus, antes passivo e manipulado pelas forças sociais, passa a ser capaz de esboçar as suas intenções, estratégias e cálculos, se aproximando então do bomo economicus, conforme ressaltou Boudon ${ }^{15}$. Com efeito, o novo tempo social, marcado pela crise do modelo tradicional do Estado-providência, levaria todos a uma nova consciência social. A partir daí a sociedade civil, antes anestesiada pelos excessos intervencionistas do Estado, se manifestou no sentido de encontrar alternativas ao vazio social. Nessa hipótese, os atores sociais se distanciam da noção de que o Estado seria o provedor natural das necessidades dos indivíduos e passaram a agir com vistas à construção de novas estruturas sociais, consideradas autônomas em relação ao Estado em crise.

Essa restruturação social não poderia avançar, entretanto, sem o concurso daqueles que contribuíram, justamente, para o início do processo: o Estado e o mercado. Ambos falharam e, por isso, era preciso encontrar o paliativo necessário a uma situação social que se agravava de mais em mais. Se, antes, havia sido detectada uma disputa pela riqueza social gerada tanto pelo Estado quanto pelo mercado, situação na qual a minoria organizada e parte do movimento sindical já haviam se colocados em posições estratégicas do ponto de vista político, cabia aos demais segmentos da sociedade civil encontrar os meios indispensáveis à sustentação do grande projeto da reestruturação social. É importante notar que esta expressão é utilizada aqui para apontar o trabalho dos movimentos sociais com vistas a preencher o vazio social. Os novos movimentos sociais como produtos da sociedade

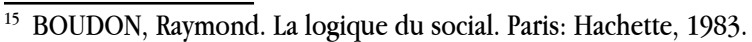


pós-industrial emergente, na forma conceituada por Touraine, geraram conflitos que despertaram a atenção dos sociólogos com o intuito de compreender a metamorfose social em curso" ${ }^{16}$. Blumer já havia abordado o tema ao proferir que "Social movement can be viewed as collective enterprises to establish a new order of life"17. Dessa forma, uma nova ordem, fundada na dinâmica social de Tocqueville e impregnada pela insatisfação de todos, seria levada às ruas, a exemplo do que havia ocorrido por ocasião da mudança social do Século XIX. A crise do Estado levaria a um movimento ordeiro, nascido no seio da sociedade civil que se organizou com vistas a preencher o vazio social e criar, assim, uma nova ordem de vida.

Por outro lado, essa iniciativa permitiu a maior participação de setores da sociedade na redistribuição da riqueza social em face do tratamento tributário oferecido pelo Estado, aos setores mais organizados da sociedade civil. Seria uma forma de compensação tendo em vista que as ações desses grupos se localizam, em sua maioria, em áreas nas quais o Estado se faz presente de forma precária ou até mesmo se ausenta de suas funções primordiais. Portanto, essa espécie de compensação levaria ao engajamento de outros segmentos sociais, funcionando como um spillover haja visto o alcance e o êxito obtido por essas inciativas na paisagem social contemporânea.

O espaço político no qual se constitui boa parte dos atuais sistemas tributários, onde a disputa pela riqueza social auferida pelo Estado exigiria a disponibilização de um quadro jurídico para justificar a redistribuição atraiu grupos que, de uma forma ou de outra, teriam meios para influenciar a produção da norma de acordo com os seus interesses. A ausência de inciativas da sociedade civil poderia levar a uma maior apropriação privada da riqueza social com efeitos ainda mais nefastos sobre as desigualdades sociais. Em realidade, o processo redistribuidor se concentraria nas mãos de uma minoria organizada. Infere-se, portanto, que a organização da sociedade civil com vistas a preencher o vazio social deixado pelo mercado e pelo Estado em crise se constitui em um trunfo importante para o progresso social evidenciando, contudo, uma disputa pela riqueza social levando, dessa forma, à disputa de classes de Marx que ainda permanece latente na paisagem sociopolítica contemporânea.

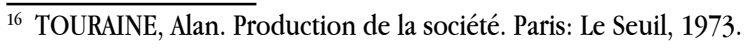

${ }_{17}$ BLUMER, H. Collective Behavior. Outline of the Principals of Sociology, New York, Barnes \& Noble, $\quad$ 1939, p. 225. 


\subsection{A NOÇÃO DE SOCIEDADE CIVIL, A DEMOCRACIA PARTICIPATIVA E A COESÃO SOCIAL}

Apesar de se recorrer aqui de forma reiterada à noção de sociedade civil, qual seria efetivamente o seu conceito? Audier, ao expor o seu entendimento sobre a matéria, colocou-a no universo da justiça social e do associativismo ${ }^{18}$. Entretanto, seria a partir de Barber que o tema seria forjado de forma mais ampla tendo o mesmo ressaltado que o termo sociedade civil se tornou um "slogan chic" e confuso. Em decorrência, apontou três versões para explicar o conceito de sociedade civil as quais foram corretamente assimiladas por Audier. A primeira versão, a dos ultraliberais, reduz a expressão, a partir de uma apologia do mercado, à noção de setor privado. A segunda, prossegue Audier, traz a noção de comunidade (communautariens) e, por fim, a terceira versão, exporia a sociedade civil como "chave para reabilitar o republicanismo", fundado sobre as formas de democracia participativa, notadamente pela vida associativa. Hirts, por sua vez, defendeu o modelo associative democracy, nascido na estirpe intelectual de esquerda dos Estados Unidos, o qual seria a verdadeira Terceira Via, em oposição à Terceira Via do trabalhismo inglês. Stiglitz, ao justificar as origens da Terceira Via ressaltou que as limitações dos governos e dos mercados levaram, em todo o mundo, à eclosão deste movimento ${ }^{19}$. Assim, foi visto que o funcionamento livre do mercado e o laissez-faire não funcionam e o socialismo e o controle do governo sobre a economia também não e por isso a Terceira Via passou a dominar a cena política ${ }^{20}$.

A crise do Estado-providência a partir dos anos setenta do Século XX desencadeou a reação de inúmeras correntes sociológicas que se colocaram, de imediato, na busca de modelos sociais alternativos. Aliás, nessa direção, ao questionar o Estado-providência, Donzelot observou que "Mudar a sociedade, se constituirá na introdução desta nova postura no interior dos comportamentos individuais e sociais, assim, militar contra os hábitos perigosos introduzidos pelo Estado-providência"²1. A percepção exposta por Donzelot se encontra no âmbito da corrente reformista que, dentre outros discursos, pugnava pela crítica ao hábito de sempre se esperar tudo do Estado, nos moldes propostos pelo socialismo de cátedra alemão.

\footnotetext{
${ }^{18}$ AUDIER, Serge. Le socialisme libéral. Paris: La Découverte, 2006, p. 101.

${ }^{19}$ STIGLITZ, Joseph. Globalization and the economic role of the state in the new millenium. Industrial and Corporate Change, New York, 12, 1, p. 03-26, 2003, p. 09.

${ }^{20}$ Ibid.

${ }^{21}$ DONZELOT, Jacques, op. cit., p. 120.
} 
No século seguinte, Eisfeld introduziria a noção do pluralismo e um projeto socialista fundado em associações em face do risco de uma via plebiscitária e tecnocrata dominada por empresas. Por isso, a intervenção pública deveria ocorrer em um sentido igualitário e pluralista ${ }^{22}$, sendo que uma destas vertentes contemplaria o associativismo. Hirst pregava que a contrarrevolução neoliberal, a crise do Welfare State e do civismo, imporiam, dentre outras, uma mutação doutrinária, reforçando a ideia do associativismo socialista ${ }^{23}$. Assim, esse socialismo libertário abriria uma terceira via entre o socialismo coletivista do Estado e o laissezfaire capitalista. Portanto, este seria o lócus do Terceiro Setor. Segundo Audier, somente a vida associativa responderia ao pluralismo e seria necessário promover os grupos solidários e, nessa medida, defendeu que "L'État doit donc non pas se désengager - comme dans le modèle libéral - mais agir indirectement en restant le garant du bon fonctionnement du tissu associatif" ${ }^{\text {"24 }}$

Seria esse, portanto, o papel atribuído ao Estado? Não se trata de uma questão fácil de responder. A alternância, ou melhor, a primazia que vem sendo dada a esta ou àquela corrente doutrinária deixa a todos sem fôlego para melhor discernir sobre qual o efetivo papel do Estado nos tempos da pós-modernidade. Sobre essa observação, seria importante destacar que Stiglitz apontou a falta de confiança daqueles que se preocupam com justiça social e com as desigualdades e há muito perderam a fé no mercado e no Estado, não confiando mais em nenhum deles ${ }^{25}$.

Todavia, há que se convir que o Estado regula a sociedade civil, mas é graças a esta que ele pode continuar um Estado democrático por meio de um equilíbrio complexo, conforme observou Audier ${ }^{26}$.

\section{O PAPEL ESTRATÉGICO DO TERCEIRO SETOR NO BRASIL}

O termo "Terceiro Setor" ainda é pouco usual no Brasil e circulado em ambientes restritos aos profissionais que, de forma direta ou indireta, atuam neste setor. Entretanto, esta expressão coexiste com várias outras terminologias que frequentemente remetem à mesma ideia: organizações sem fins lucrativos,

\footnotetext{
${ }^{22}$ AUDIER, Serge, op. cit., p. 106.

${ }^{23}$ HIRST, Paul. From statism to Pluralism. Londres: UCL Press, 1997, p. 46.

${ }^{24}$ AUDIER, Serge, op. cit., p. 104.

25 STIGLITZ, Joseph, op. cit., p. 12.

${ }^{26}$ AUDIER, Serge, op. cit., p. 107.
} 
organizações da sociedade civil organizada, organizações não governamentais (ONGs), setor público não estatal, organizações sociais, instituto, associações, fundações, entre outros. Esta imprecisão conceitual revela a grande dificuldade que se tem em enquadrar a heterogeneidade dessas organizações em parâmetros comuns, dificultando a compreensão desse fenômeno social.

Diante disso, é importante compreender o que de fato é o Terceiro Setor e que tipo de organização o integra. A expressão "terceiro setor" pressupõe a existência de um primeiro, composto pelo Estado e de um segundo, caracterizado pelos valores próprios do mercado. Assim, o Terceiro Setor integra as organizações de iniciativa privada mas sem finalidades lucrativas e que desempenham atividades de interesse público. Para Santos essas organizações "por um lado sendo privadas não visam fins lucrativos, e por outro lado, sendo animadas por objetivos sociais, públicos ou coletivos, não são estatais" ${ }^{\prime 2}$. Neste sentido, o Terceiro Setor abrange ainda as iniciativas filantrópicas de caráter empresarial.

No intuito de contribuir para a construção de uma identidade comum para estas organizações, o Centro de Estudos da Sociedade Civil da Universidade John Hopkins, nos EUA, liderado pelo professor Lester Salamon, apontou cinco características comuns a todas as organizações do Terceiro Setor: são privadas; não têm fins lucrativos; são institucionalizadas, ou seja, legalmente constituídas; são autoadministradas e possuem algum grau de participação voluntária ${ }^{28}$. Estes são os mesmo critérios considerados na pesquisa realizada pelo Instituto Brasileiro de Geografia e Estatística - IBGE e o Instituto de Pesquisa Econômica Aplicada IPEA, sobre as Fundações Privadas e Associações sem Fins Lucrativos - FASFIL, todos atuantes no território brasileiro.

No Brasil, a origem de organizações voluntárias de cunho social aconteceu através das igrejas cristãs, que fundaram as "Santas Casas de Misericórdia" a partir do Século XVI, conforme o modelo trazido de Portugal. Estas instituições, com suas ações filantrópicas, tinham a finalidade de atender e assistir as questões sociais, sendo este o modelo assistencialista que predominou durante todo o período colonial. Já no início do Século XX, novas organizações da sociedade civil começaram a ser formadas para atender às necessidades sociais.

\footnotetext{
${ }^{27}$ SANTOS, Boaventura de Souza. A reinvenção solidária e participativa do Estado. In: Pereira, L. C. Bresser (Org.). Sociedade e Estado em transformação. São Paulo: UNESP, 2001, p. 13.

${ }^{28}$ SALAMON, Lester. A emergência do terceiro setor: uma revolução associativa global. Revista de Administração de Empresas da FGV, São Paulo, v. 33, p. 5-11, jan./mar. 1998.
} 
Entretanto, a partir das décadas de 1970 e 1980 emergem as organizações contrárias ao governo e de caráter reivindicatório e que lutam pela conquista de direitos sociais. Por tudo isso, estas passam a ser denominadas como "ONGs" (Organizações Não Governamentais), e que até os dias atuais é o termo mais comumente usado para se referir às organizações do Terceiro Setor, mesmo que caracterizadas como agentes propositivos e não mais por ações de negação ao governo.

Caracterizar essas organizações como "aquilo" que não é governo para o contexto atual se mostra insuficiente para descrever a real natureza do fenômeno. Atribuir essa característica ao Terceiro Setor revela uma incoerência entre conceito e a realidade concreta. O que se observa é uma crescente parceria e complementariedade nas atividades do Terceiro Setor para com a responsabilidade social do Estado. Além disso, segundo Gohn, as organizações que emergiram na década de 1990 não são as mesmas que lutaram contra o governo nas décadas anteriores, se definindo pelo que são e não pelo que não são usando o termo Terceiro Setor ${ }^{29}$.

$\mathrm{O}$ período de redemocratização brasileira, no final do Século $\mathrm{XX}$, ficou marcado por uma intensa participação das "ONGs" que contribuíram para fortalecer e acelerar o processo, o que resultou na emergência de uma sociedade civil mais autônoma e ativa na vida pública. Portanto, mais do que organizações que trabalham em torno da questão social, o Terceiro Setor representa um fenômeno de transformação social que caracteriza profundas mudanças na sociedade contemporânea. A emergência dessas organizações evidencia um amadurecimento democrático da sociedade a qual se sente responsável ante à desigualdade e exclusão social.

Entretanto, é preciso considerar o período histórico de evolução não apenas do conceito de utilidade pública consagrado na Lei $\mathrm{n}^{\circ}$ 91/1935, sancionada ainda na época de Vargas no poder, a qual foi revogada recentemente pela Lei $\mathrm{n}^{\mathrm{o}}$ 13.204/2015 que dispôs sobre as modalidades de organização da sociedade civil. É importante observar que este diploma legal introduziu alterações também na Lei $\mathrm{n}^{\mathrm{0}}$ 13.019/2014, o qual estabeleceu o regime jurídico aplicável nas parcerias entre a administração pública e a sociedade civil. Considerando, portanto, a preocupação do Estado brasileiro em consolidar a parceria com os segmentos organizados da sociedade civil, a Lei n ${ }^{\circ} 9.790 / 1999$, com a redação posterior dada pela já mencionada

${ }^{29}$ GOHN, Maria da Glória. O novo associativismo e o Terceiro Setor. Serviço Social e Sociedade. São Paulo, Cortez, ano XIX, n. 58, nov. 1998, p. 13. 
Lei $\mathrm{n}^{\mathrm{o}}$ 13.019/2014, definiu que se enquadraria como organização da sociedade civil de interesse público (OSCIP), as pessoas jurídicas de direito privado sem fins lucrativos. Deve ser levando ainda em conta, que outra contribuição importante dada pela referida Lei ${ }^{0}$ 9.790/1999 se deu na introdução e no disciplinamento do conceito do termo de parceria, o que se constituiu em um passo significativo para a definição do quadro jurídico norteador do Terceiro Setor no Brasil.

É importante destacar, ainda, a contribuição da Constituição Federal de 1988 para a criação de novos espaços de atuação das organizações do Terceiro Setor. Ao instituir o conceito de Seguridade Social e estabelecer que o Estado e a sociedade sejam responsáveis pela promoção dos direitos sociais, a Carta Magna colaborou significativamente para um ambiente propício à participação ativa das organizações da sociedade na esfera pública. A Constituição estabeleceu novos direitos sociais. Contudo, esta evolução não foi acompanhada por uma maior disponibilidade de recursos. Assim, o Estado, mesmo tendo assumido novos compromissos não tem sido capaz de cumprir com todos os seus deveres sociais.

Após a Constituição Federal de 1988, ocorreram vários avanços legais que marcaram as relações entre o Estado e a organizações não governamentais, refletindo com isso uma crescente importância e relevância dessas organizações. A década de 1990 foi marcada pelo marco regulatório que resultou na reforma do Estado iniciada em 1995 e teve como foco a "publicização", ou seja, a terceirização do serviço público no limite possível.

Em tempos recentes, após pressões e mobilizações sociais, foi possível estabelecer um novo marco regulatório das relações entre o Estado e as organizações da sociedade civil, o que resultou na Lei $\mathrm{n}^{0} 13.019 / 2014$, alterada posteriormente pela Lei $\mathrm{n}^{0} 13.204 / 2015$, como assinalado acima. Apesar de não abranger todas as questões desejadas e necessárias, esta lei representou um avanço significativo e importante no ordenamento jurídico brasileiro e contribuiu para o reconhecimento dessas organizações com atores relevantes na vida pública do País.

O Terceiro Setor, mais do que um conjunto de organizações sem fins lucrativos e com finalidades de interesse público, reflete uma profunda transformação social em diversos aspectos. A emergência dessas organizações evidencia uma ruptura na dicotomia entre Estado e mercado, caracterizando então o anseio por um novo tipo de democracia que não seja exclusivamente representativa, mas também participativa. Caracteriza ainda a mudança de valores dos indivíduos que, aos 
poucos, se tornam cidadãos responsáveis pelo ambiente em que vivem e se fazem ativos na promoção dos direitos sociais e na solução de problemas comunitários. Esse aspecto se constituiu também em um dos fundamentos da Economia Social. Batifoulier asseverou que "La citoyenneté de l'individu est forgée par son identité sociale", o que estabelece um laço importante entre cidadania e responsabilidade ${ }^{30}$.

\subsection{A ATUAÇÃO DO TERCEIRO SETOR NA PRESTAÇÃO DE SERVIÇOS PÚBLICOS}

Muitos defensores do Terceiro Setor veem neste a promessa de renovação da esfera pública por meio da humanização do capitalismo, da superação da pobreza e das desigualdades. Entretanto, trata-se de uma visão ideológica e quase utópica. $\mathrm{O}$ fato é que este setor tem um caráter estratégico capaz de fazer frente aos problemas sociais mas apenas a partir de parcerias estabelecidas com o Estado e o mercado. É uma maneira alternativa e eficaz de conduzir políticas públicas, no âmbito da seguridade social, por exemplo, sem tirar, contudo, essa responsabilidade do Estado.

Até 2006, o número de organizações do Terceiro Setor cresceu exponencialmente. Mesmo após um período de desaceleração, um crescimento importante deste segmento foi registrado. Na década de 1970, esse crescimento foi da ordem de $88 \%$ e na década de 1980 foi de $124 \%$, tendo alcançado $157 \%$ em apenas seis anos, no período compreendido entre 1996 e 2002. Entretanto, de 2006 a 2010, apesar do crescimento verificado, este foi menos expressivo, da ordem de $8,8 \%$, chegando a 290,7 mil organizações, conforme a pesquisa FASFIL realizada pelo IBGE em $2010^{31}$.

A partir da década de 1990, simultaneamente a esse crescimento, o papel social do Terceiro Setor começou a ser formalmente reconhecido, havendo uma maior regulamentação da parceria com o Estado no ordenamento jurídico brasileiro como resultado da reforma do aparelho do Estado realizada em 1995. Desde então, vem aumentando sua contribuição com a produção de bens públicos, se caracterizando como um agente social competente e ativo no enfrentamento dos crescentes problemas sociais. Essas organizações são capazes de intervir na agenda pública, atuam na execução de políticas sociais e inovam com projetos de caráter público.

\footnotetext{
${ }^{30}$ BATIFOULIER, Philippe, op. cit., p. 117.

${ }^{31}$ IBGE, GIFE, ABONG e IPEA. As Fundações privadas e associações sem fins lucrativos no Brasil 2010 (FASFIL 2010). Rio de Janeiro: IBGE, 2012.
} 
A função social dessas organizações não visa à substituição do Estado em suas atividades, mas de complementá-las, até mesmo porque sem a presença do Estado, o Terceiro Setor estaria fadado ao insucesso. Assim, essas organizações atuam como parceiras na execução e elaboração de políticas públicas, contribuindo para a efetivação dos direitos sociais previstos na Constituição Federal de 1988.

Quase sempre as organizações sem fins lucrativos são mais eficientes e eficazes na tarefa de executar e promover políticas sociais do que o Estado. Estas organizações se mostram mais eficientes por possuírem uma estrutura organizacional menor e mais dinâmica, e por estarem mais próximas do beneficiário final. Como emergem da própria sociedade, conseguem perceber de maneira mais incisiva suas aspirações, e assim oferecer um melhor atendimento aos beneficiários a um custo menor.

De acordo com Hans Brinswanger, ex-diretor da área de desenvolvimento rural do Banco Mundial, de cada US $\$ 100$ liberados para o Brasil, apenas US\$60 chegavam aos beneficiários finais. Assim, "com as parcerias comunitárias, via ONGs, chegam mais de $90 \%$, ou seja, o dinheiro do banco deixou de sustentar estruturas pesadas da burocracia estatal e passou a render mais" ${ }^{32}$. Esta percepção do Banco Mundial reforça o entendimento de que essas organizações são capazes de executar projetos sociais de forma mais eficiente que o Estado.

Entretanto, para garantir resultados significativos e coerentes, essas organizações da sociedade civil não podem atuar separadamente. É fundamental que atuem de maneira intersetorial e em redes. Esta prática potencializa a capacidade dos atores públicos, tanto do Estado quanto das organizações do Terceiro Setor, na obtenção de resultados de maior repercussão. Os governos têm aumentado seu apoio às organizações da sociedade civil na execução de serviços públicos, acarretando assim um custo menor no cumprimento de suas responsabilidades sociais, além de promover uma democracia mais participativa.

A crise do Estado de bem-estar social ocorrida a partir da década de 1970 causou uma redução significativa no financiamento das políticas sociais. Desta forma, a parceria do Estado com o Terceiro Setor, através do fomento de seus projetos, consiste em uma estratégia para obter uma maior eficiência no uso dos escassos recursos públicos, que podem e são muitas vezes melhor geridos pelas organizações sem fins lucrativos.

$\overline{32}$ RODRIGUES, Maria Cecília Prates. ONG tomou-se senha para acesso a verbas. Demandas sociais versus crise de financiamento: o papel do terceiro setor no Brasil, Revista de Administração Pública, Rio de Janeiro, v. 39, n. 5, 1998, p. 43. 
O fomento também contribui para a descentralização política e administrativa do Estado. Segundo Rocha o fomento é uma ação dirigida a proteger ou promover as atividades e estabelecimentos dos particulares que satisfaçam necessidades públicas ou que sejam consideradas de utilidade geral ${ }^{33}$. Por isso, a descentralização das políticas públicas permite uma prestação de serviços menos burocráticos e mais eficientes.

No Brasil, as atividades de fomento têm tido um crescimento expressivo nos últimos anos, contribuindo significativamente para o aumento das organizações do Terceiro Setor, o que representa uma mudança profunda na forma de participação da sociedade civil no setor público. Por meio do fomento, grupos sociais menores encontram o cenário propício para atuarem ativamente na vida pública, tornando protagonistas nos assuntos em que são mais competentes do que o Estado para gerir. E, ainda, essas organizações se caracterizam como espaço apropriado para a concretização da cidadania ativa e participativa.

Por intermédio do Terceiro Setor, a sociedade civil passa a exercer uma cidadania participativa de forma direta e independente, isto é, as organizações do Terceiro Setor se tornam um ambiente onde os indivíduos podem ser ativos na esfera pública e atuantes na transformação da realidade social. Além disso, diante de uma crise da democracia representativa, o cidadão brasileiro não se sente mais representado pelos partidos políticos ou sindicatos e passa a demandar por uma democracia participativa. Existem vários espaços onde é possível exercer essa cidadania mais atuante e legítima por meio da sociedade civil institucionalizada: os conselhos setoriais de políticas públicas, as conferências, as audiências e consultas públicas, dentre outros.

O Terceiro Setor contribui também de forma significativa para a construção do capital social. Por meio de sua atuação intersetorial e em rede, essas organizações colaboram com novas ideias, conhecimentos e ações, além de mobilizar numerosos recursos não só financeiros e materiais, mas principalmente humanos. Os valores morais presentes nessas organizações também contribuem para a geração de capital social ao facilitarem a cooperação e o associativismo. Um exemplo muito claro é a participação voluntária, fator intrínseco a essas organizações, representando a capacidade do indivíduo que, movido pelo valor de solidariedade, doa seu tempo para causas de interesse público.

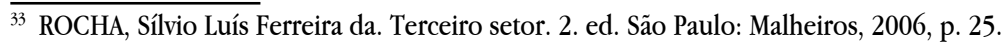


Outra contribuição social importante dessas organizações está relacionada com o seu potencial de gerar empregos. Segundo o estudo FASFIL, em 2010 este setor empregava 2,1 milhões de trabalhadores assalariados ${ }^{34}$. Esse número representa $23 \%$ do total de empregados na administração pública e 4,9\% do total de trabalhadores brasileiros. Nesse aspecto, inclusive, Rifkin chega a apontar o Terceiro Setor como a maior fonte de empregos no futuro ${ }^{35}$.

É importante lembrar que estes valores não incluem a força voluntária, tão presente nas organizações do Terceiro Setor. No Brasil, ainda não existem estudos quantitativos quanto à participação voluntária nessas organizações. Nos EUA, estimase que $90 \%$ da população já participaram ou participam de atividades voluntárias com foco social. Obviamente que esse dado está distante da realidade brasileira. Todavia, é preciso ter em vista que a força de trabalho voluntária no Terceiro Setor não só existe como representa valores expressivos capazes de contribuir significativamente para a construção de capital social.

As iniciativas de caráter privado e finalidade social não estão limitadas pelas ações da sociedade civil, sendo cada vez mais frequente a participação do mercado neste processo. A partir da década de 1990 surge um novo conceito na administração de empresas, o de responsabilidade social, onde empresas do mercado começam a atuar em relação aos problemas sociais. Segundo a ISO 26000, responsabilidade social é a responsabilidade de uma organização perante os impactos que suas decisões e atividades causam na sociedade e no meio ambiente, por meio de uma conduta ética e transparente. Ou seja, praticar a responsabilidade social é uma forma das empresas serem responsáveis por aqueles que são afetados por suas práticas. De modo geral, uma empresa pode atuar na esfera social de duas maneiras. $\mathrm{Na}$ primeira hipótese a empresa cria sua própria associação ou fundação, ao instituir outra pessoa jurídica. Por sua vez, na segunda hipótese, a empresa poderá fazer doações às organizações do Terceiro Setor já existentes, se tornando um parceiro importante neste caso.

O Estado não é a única fonte de financiamento do Terceiro Setor, fato que fortalece mais ainda essas organizações. Estas, em busca de maior autonomia e independência, vêm concentrando esforços para sensibilizar o mercado e os indivíduos a contribuírem com recursos materiais, financeiros e humanos para as atividades de iniciativa privada e de interesse público.

${ }^{34}$ IBGE, GIFE, ABONG e IPEA, estudos realizados no âmbito da FASFIL.

${ }^{35}$ RIFKIN, Jeremy. O fim dos empregos: o declínio inevitável dos níveis de empregos e a redução da força global de trabalho. Sã̃o Paulo, Makron Books, 1995, p. 310. 


\subsection{PERSPECTIVAS E DESAFIOS PARA O TERCEIRO SETOR NO BRASIL: A NECESSIDADE DE UM QUADRO JURÍDICO CONSOLIDADO}

O debate quanto à participação do Terceiro Setor na execução de serviços públicos não é mais coerente, a importância que as organizações deste setor alcançaram não é reversível, e nem tem motivos para sê-lo. O que deve ser discutido é qual a melhor forma de estruturar estas organizações para que alcancem uma maior eficiência e transparência na realização de suas atividades organizacionais.

Mesmo ganhando cada vez mais destaque e importância, as organizações do Terceiro Setor têm à sua frente desafios que precisam ser superados a fim de fortalecer e ampliar as sua capacidade de influenciar na deliberação, elaboração, implementação e fiscalização de políticas públicas. Existe um grande vazio teórico no estudo sobre o Terceiro Setor nas distintas áreas do conhecimento, valorizar esse estudo é elemento importante no processo de consolidação e legitimação do segmento.

Primordialmente, existe uma grande dificuldade em construir uma identidade comum a todas as organizações da sociedade civil de forma a esclarecer qual seria a sua real natureza e objetivos. A pluralidade temática dessas organizações, a diversidade de termos para defini-las e a ausência de dados e informações são fatores que precisam ser superados para a consolidação do setor. Além do mais, uma identidade única permitirá que se tenha uma ideia mais aproximada da real dimensão e impacto deste setor e consequentemente de sua função efetiva para a vida social.

Mesmo com o aumento da atuação em rede dessas organizações, é necessário ampliar o diálogo intrasetorial, pois este mecanismo contribui muito para o desenvolvimento de novas competências e permite o compartilhamento de capacidades e conhecimentos. Ou seja, o aperfeiçoamento das comunicações entre as organizações do Terceiro Setor pode colaborar em muito com o desempenho de suas atividades.

No que diz respeito à capacidade dessas organizações em prestar serviços públicos, fica evidente a sua eficiência em fazê-lo. Entretanto, essa característica não pode encobertar a necessidade de se profissionalizar cada vez mais suas atividades. Uma maior profissionalização, baseada nas regras de mercado, trará melhores resultados além de facilitar as trocas e reproduções de conhecimento para a obtenção contínua de melhores resultados. 
Existe um vácuo na regulamentação da fiscalização dessas organizações no Brasil o qual precisa ser preenchido por métodos que ultrapassem meros relatórios contábeis e que possam, de fato, avaliar o impacto social e a qualidade dos projetos executados. Afinal, é na esfera legal que a responsabilidade do Terceiro Setor pode se manifestar com maior visibilidade e confiabilidade.

Além disso, a transparência do Terceiro Setor é fator fundamental para que essas organizações alcancem um status de credibilidade. No Brasil, por exemplo, a mídia noticia apenas os casos de corrupção envolvendo as organizações do Terceiro Setor e dá pouco ou nenhum espaço para os casos bem sucedidos e de profundo impacto social. Ainda existe um longo caminho a ser percorrido no sentido de se implantar métodos e ferramentas mais adequados para a tarefa de promover a transparência do Terceiro Setor. Sem isso, essas estruturas institucionais estarão sujeitas a se tornarem instrumentos de corrupção e barganha, fator que dificulta $o$ fortalecimento e a consolidação do setor, além de desvalorizar o trabalho competente que é realizado pelas organizações.

A questão da sustentabilidade talvez seja o maior desafio a ser enfrentado pelo Terceiro Setor. A parceria com o Estado é importante e a atividade de fomento é essencial para a execução dos projetos. Porém, para garantir a continuidade do seu trabalho, essas organizações não podem depender de uma única fonte de recursos. É necessário que estratégias sejam traçadas para garantir a variedade dos meios, principalmente os financeiros.

Entretanto, a sustentabilidade viria por meio da consolidação do quadro jurídico que rege a espécie. Com efeito, o conjunto de normas esparsas não seria suficiente pra definir o marco regulatório do Terceiro Setor no Brasil. A edição de diversos diplomas legais, dentre eles a Lei $\mathrm{n}^{0} 13.019 / 2014$, a Lei $\mathrm{n}^{0} 13.102 / 2015$ e a Lei $n^{0} 13.204 / 2015$, exige um esforço de harmonização jurídica que poderia levar ao desencadeamento de um processo de codificação das diversas normas incidentes sobre a matéria.

\section{CONCLUSÃO}

O presente trabalho se esforçou no sentido de contribuir para o debate em torno do papel estratégico do Terceiro Setor, mais especialmente no Brasil. Antes, contudo, fez-se necessária a elaboração de um escorço teórico com supedâneo 
na formulação de Gide acerca da Economia Social. Com toda evidência, a análise proposta não esgota o tema, o que seria uma pretensão desmesurada. Trata-se apenas de uma instigação ao debate haja vista o impacto restrito que o Terceiro Setor tem obtido junto à sociedade civil.

Restam ainda questões importantes a serem discutidas. O papel do Terceiro Setor na configuração da pós-modernidade, onde a busca por uma estética mais humana do capital começa a fazer parte da agenda em face, talvez, do esgotamento dos modelos até agora colocados em prática. Seria o descrédito da ação do Estado ou a tão decantada lógica do mercado que teriam levado todos a perder a confiança nas duas instituições? Qualquer que seja a resposta, o que deve ser firmado é que a sociedade civil não permaneceu indiferente à nova questão social que emergiu da crise econômica internacional e do fim dos Trinta Gloriosos na segunda metade dos anos setenta do Século 20. A partir dali, a crise do Estado-providência e o delineamento de um novo Estado culminaram no agravamento das desigualdades sociais. Assim, com vistas a restabelecer ou, melhor, a preservar as estruturas da coesão social e da solidariedade, como ensinado pelos fundadores da sociologia, é que a sociedade civil se lançou na busca de alternativas para preencher o vazio social. Nesse sentido, deve ser observada ainda a necessidade de uma resposta do ordenamento jurídico no sentido de considerar esses fatos sociais. Por isso, deve considerar a necessidade de consolidação do aparato legal destinado a sustentar estas iniciativas. Foi nessa direção a proposta esboçada pelo presente trabalho.

\section{REFERÊNCIAS}

ARON, Raymond. Dix-huit leçons sur la société industrielle. Paris: Galimard, 1962.

AUDIER, Serge. Le socialisme libéral. Paris: La Découverte, 2006.

BATIFOULIER, Philippe. L'économie sociale. Paris: Presses Universitaires de France, 1995.

BLUMER, H. Collective Behavior. Outline of the Principals of Sociology, New York, Barnes \& Noble, 1939, p. 221-280. 
BOUDON, Raymond. La logique du social. Paris: Hachette, 1983.

DONZELOT, Jacques. L'invention du social. Paris: Éditions du Seuil, 1994.

FITOUSSI, Jean-Paul; ROSANVALLON, Pierre. Le nouvel âge des inégalités. Paris: Éditions du Seuil, 1996.

GIDE, Charles. Principes d'Economie Politique. Paris: Recueil Sirey, 1913.

GOHN, Maria da Glória. O novo associativismo e o Terceiro Setor. Serviço Social e Sociedade, São Paulo, Cortez, ano XIX, n. 58, nov. 1998.

HIRST, Paul. From statism to Pluralism. Londres: UCL Press, 1997.

IBGE, GIFE, ABONG e IPEA. As Fundações Privadas e Associações sem Fins Lucrativos no Brasil 2010 (FASFIL 2010). Rio de Janeiro: IBGE, 2012.

PIRIOU, Jean-Paul. Lexique des sciences économiques et sociales. 4. ed. Paris: La Découverte, 2001.

RIFKIN, Jeremy. O fim dos empregos: o declínio inevitável dos níveis de empregos e a redução da força global de trabalho. São Paulo: Makron Books, 1995.

ROCHA, Sílvio Luís Ferreira da. Terceiro setor. 2. ed. São Paulo: Malheiros, 2006.

RODRIGUES, Maria Cecília Prates. Demandas sociais versus crise de financiamento: o papel do terceiro setor no Brasil. Revista de Administração Pública, Rio de Janeiro, v. 39, n. 5, p. 25-67, 1998.

RODRIGUES, Maria Cecília Prates. ONG tomou-se senha para acesso a verbas. Demandas sociais versus crise de financiamento: o papel do terceiro setor no Brasil. Revista de Administração Pública, Rio de Janeiro, v. 39, n. 5, 1998, p. 43.

ROSANVALLON, Pierre. La nouvelle question sociale. Paris: Éditions du Seuil, 1995.

SALAMON, Lester. A emergência do terceiro setor: uma revolução associativa global. Revista de Administração de Empresas da FGV, São Paulo, v. 33, p. 5-11, jan./ mar. 1998. 
SANTOS, Boaventura de Souza. A reinvenção solidária e participativa do Estado. In: Pereira, L. C. Bresser (Org.). Sociedade e Estado em transformação. São Paulo: UNESP, 2001.

STIGLITZ, Joseph. Globalization and the economic role of the state in the new millenium. Industrial and Corporate Change, New York, 12, 1, p. 03-26, 2003.

TOURAINE, Alan. Production de la société. Paris: Le Seuil, 1973.

WALRAS, Léon. Éléments d'économie politique. Paris: Librairie Général de Droit et de Jurisprudence, 1952.

WEBER, Max. Economie et société: l'organisation et les puissances de la société dans leurs rapports avec l'économie. Tradução de Julien Freund et alii. Paris: Plon, 1971.

Recebido em: 28 de julbo de 2016 Aceito em: 21 de dezembro de 2016 